\title{
Participation in rural community groups and links with psychological well-being and resilience: a cross-sectional community-based study
}

\author{
Anthony Lyons ${ }^{1 *}$, Gillian Fletcher ${ }^{2}$, Jane Farmer ${ }^{3}$, Amanda Kenny $^{3}$, Lisa Bourke ${ }^{4}$, Kylie Carra ${ }^{3}$ and Emily Bariola ${ }^{1}$
}

\begin{abstract}
Background: Fostering the development of community groups can be an important part of boosting community participation and improving health and well-being outcomes in rural communities. In this article, we examine whether psychological well-being and resilience are linked to participating in particular kinds of rural community groups.

Methods: We conducted a household survey involving 176 participants aged 18 to 94 years from a medium-sized rural Australian town. We gathered data on psychological well-being (Warwick-Edinburgh Mental Well-being Scale), resilience (Brief Resilience Scale), and the types of community groups that people participated in as well as a range of characteristics of those groups, such as size, frequency of group meetings, perceived openness to new members, and whether groups had leaders, defined roles for members, hierarchies, and rules.

Results: Univariable regression analyses revealed significant links between particular group characteristics and individual psychological well-being and resilience, suggesting that the characteristics of the group that an individual participates in are strongly tied to that person's well-being outcomes. Multivariable analyses revealed two significant independent factors. First, psychological well-being was greatest among those who participated in groups without a hierarchy, that is, equal-status relationships between members. Second, resilience was greater among those who reported having a sense of influence within a group.
\end{abstract}

Conclusions: Our findings suggest that policymakers wishing to promote participation in rural community groups for health and well-being benefits may do well to encourage the development of particular characteristics within those groups, in particular equal-status relationships and a sense of influence for all group members.

Keywords: Rural, Community participation, Mental health, Well-being, Resilience

\section{Background}

Approximately $31 \%$ of Australian residents live in regional or rural areas [1]. As in many developed countries, there has been a net population shift in Australia away from rural and remote communities to urban centers, especially in areas that are far from urban centers [2]. Some of this is the result of young people relocating to

\footnotetext{
* Correspondence: a.lyons@latrobe.edu.au

${ }^{1}$ Australian Research Centre in Sex, Health and Society, School of Psychology and Public Health, La Trobe University, 215 Franklin Street, Melbourne, Victoria 3000, Australia

Full list of author information is available at the end of the article
}

cities in pursuit of educational and employment opportunities [3]. In some places, it is also due to a restructuring in the agricultural sector resulting in less employment in this sector [2]. One major driver of decline is an historical reduction in the terms of trade in global markets for agricultural products, such as wool and wheat, that have led to lower profits [2]. Industrialization of agriculture has also led to a greater centralization of agricultural production and lower employment [4].

With large numbers of younger people moving to urban centers, many rural areas in Australia have disproportionately older populations. In 2011, approximately 
$35 \%$ of Australians aged 65 years and older were living in regional and rural areas [5, 6]. Despite this, rural and remote communities tend to have poorer access to health and social support services [7]. Yet, the rapid restructuring of rural Australia has been shown to have a negative impact on the health and well-being of residents living in areas of social and economic decline [2].

In response to these and similar trends globally, policymakers in Australia and internationally have sought innovative and cost-effective strategies to help support the well-being of rural residents, such as initiatives to promote community participation [8] and community co-production of services $[9,10]$. Many such initiatives are also aimed at building individual resilience in rural communities to prevent health problems [11]. Although conceptualized in different ways [12], it is generally accepted that resilience, at a minimum, refers to an individual displaying a tendency to bounce back or recover quickly from challenging life events [13]. Resilience can be strengthened through enhanced social relationships [12] and is highly protective of a range of health problems [14].

Psychological well-being and resilience tend to be greater among individuals who report high levels of community involvement and social support [15-18]. Despite major social and economic changes, rural communities are often suggested to have greater community connectedness than urban communities [19], manifested in greater social capital and volunteering [20, 21]. Community groups, such as charities, sports clubs, and arts and hobby groups, bring residents together and provide group members with opportunities to give and receive social support, such as a sense of belonging, practical help, or emotional support [22]. In fact, group involvement has been regarded as a kind of "social cure" in public health, and tends to have its largest impact on psychological well-being and resilience for individuals who participate in groups that they view as important to them or their sense of self and identity [23].

Encouraging the development of thriving community groups offers potential for supporting well-being and preventing mental health problems in rural communities, and is often a priority for policymakers interested in implementing strategies to increase community participation [19]. It is therefore important that policymakers have information on different forms of participation and its links with well-being outcomes. However, little is known about whether particular community group characteristics are associated with higher levels of psychological wellbeing and resilience than other groups. Whilst there is substantial evidence that well-being outcomes vary when people shift from one group to another [24], it is unclear whether some kinds of groups offer better outcomes than others. It is this knowledge gap that we seek to address in this article.
Community groups can be highly diverse with regard to type, size, structure, and composition. For example, Lickel and colleagues conducted cluster analyses that identified four common group types: task-focused groups; intimacy or social-focused groups; social categories, and; loose associations [25]. Among community groups, task-focused and social-focused groups are the most common. While all groups are inherently social, they vary according to the degree in which they function to fulfil particular tasks or to provide social opportunities for members. Task-focused groups may include charity groups supporting people on low incomes, groups that look after a town's parks or gardens, or groups that bring people together around a common interest, such as fishing or mountaineering. Social-focused groups may place greater emphasis on the relationships between group members, such as a support group for people who share a common problem or a group that hosts social events.

In addition to group type, groups can vary according to a range of characteristics. Some groups may have many members while others may be small. Some may allow new members to enter the group easily while others may be less open to outsiders. Some may meet often while others less so. In some groups, there may be a particular person who acts as leader. Some may also have prescribed rules of conduct, clearly defined roles for the group members, or hierarchies. Alternatively, there may be groups with a more flexible structure in which people "chip in" when needed rather than having clear roles, hierarchies, or rules. We have been unable to locate any previous studies that have examined whether community groups with differing structures and other characteristics have different levels of well-being among their members.

It could be contended that groups that are highly structured with regard to roles and rules may be better organized at providing social support to their members. Alternatively, groups that are less structured may allow more members to participate in decision-making, potentially providing a greater sense of value and worth. Within some groups, individual members might perceive themselves as having greater levels of influence within a group than other members. Examining perceived influence within a group aligns with research that demonstrates that people are generally happier if they have a sense of control over some or all aspects of their life $[26,27]$. Group leaders might naturally perceive themselves as having high levels of influence, but other group members may also feel that they play a central part in shaping the group and its activities. Despite research on the positive benefits of having a sense of control, there is little research on individual's perceived influence within a community group and links to wellbeing. 
Our study was conducted in a medium-sized rural Australian town in the western region of the state of Victoria, which will remain undisclosed to protect the town's confidentiality. According to 2011 Australian Bureau of Statistics data, the town consists of $49 \%$ male and $51 \%$ female residents. It has a large older population, with $32 \%$ aged 60 years and older compared to $20 \%$ nationally and a median age of 48 years compared to 37 years nationally. Similar to other rural centers [28], education levels are lower than the national average, with $6 \%$ having a university education compared to $14 \%$ nationally. The town was selected because of relatively high levels of community participation, with approximately $45 \%$ of residents volunteering their time in community groups and initiatives.

We examined the community groups in which residents participated as well as residents' psychological well-being and resilience. We included a focus on resilience because promoting resilience in rural and other communities has become a major focus for some government and other policymakers. As mentioned earlier, having strong social and other forms of support has also been linked with resilience [17], so it is possible that participating in some community groups enables individuals to draw on support that improves their capacity for resilience. In all, we had three main objectives: 1) to identify the most common groups in which residents participated according to types and characteristics of groups; 2) to identify whether there were links between psychological well-being and participating in groups of particular types and characteristics, and; 3) to identify whether there were links between resilience and participating in groups of particular types and characteristics.

\section{Methods}

\section{Sample}

A total of 176 participants took part in the study. All participants were residents of the town, which consisted of 1298 households and was located approximately $300 \mathrm{~km}$ from Melbourne, the capital and largest city in Victoria. Participants in our study were older on average, with an age range of 18-94 years, a mean age of 61.9 years $(\mathrm{SD}=14.5)$, and a median age of 64 years $(\mathrm{IQR}=53$ to 72 years).

\section{Survey measures \\ Sociodemographics}

Participants indicated their age, gender, employment status (coded as full-time, part-time or casual, not working), country of birth (coded as Australia or overseas), and the number of years in which they had lived in the town. Participants also indicated whether they felt a part of their community (not at all, a little bit, to a moderate degree, very much) and how much influence they believed they had within the community (none, a little, some, a lot; later coded as little or none versus some or a lot).

\section{Community group participation}

Participants were asked a series of questions about their involvement in community groups. They were specifically asked to think about the group that they felt was most important to them and to answer the questions in reference to this group. This strategy was adopted because residents may be members of multiple groups. The focus on the most important group was based on our reasoning that belonging to this group is likely to have the largest potential effect on psychological well-being and resilience. In other words, the type or characteristics of a group may have less effect on the well-being of individuals for whom the group is only a minor part of their lives or identity, as suggested by previous research on the role of group identity in health and well-being [23].

Participants were asked to indicate the type of group in an open-ended response field, such as noting whether it was a sports group (e.g., tennis club) or support group (e.g., mother's group). They were then given a list of group types and characteristics and asked to indicate which of the following were true of the group, including whether the group was formally organized, was hierarchical, had strict rules, was relatively relaxed/casual, had a leader, or had each group member's role clearly defined. They were also able to indicate whether the group was a social or task-focused group. Participants were able to select both options. A variable was therefore computed to indicate whether the group was primarily social-focused, primarily task-focused, or both. Based on questions from a previous study [29], participants were provided with the following statement, "people in this group are very similar to each other", and agreed or disagreed using a 7-point Likert scale (later coded as either agree or do not agree). Finally, participants indicated how much influence they had within the group (none, a little, some, a lot; later coded as little or none versus some or a lot), the number of group members, the length of time that the group had existed, how often the group gained new members (never, rarely, occasionally, often), and how frequently the group gets together on average (coded as one or more times a week or fortnightly/monthly). See Additional file 1 for the exact wording of questions on community group participation.

\section{Psychological well-being}

Psychological well-being was assessed with the Short Warwick Edinburgh Mental Well-Being Scale (SWEMWBS) [30], which has strong validity and reliability as a general measure of psychological well-being. It consists of seven items answered on a 5-point scale from "none of the time" to "all of the time". Examples of items include "I've been 
feeling optimistic about the future", "I've been feeling relaxed", and "I've been dealing with problems well". Scores are added to produce an overall score between 7 and 35, with higher scores indicating greater psychological wellbeing.

\section{Resilience}

Resilience was measured using the Brief Resilience Scale (BRS) [13]. The BRS is a self-reported scale and specifically measures the tendency for an individual to bounce back easily from stressful or challenging life events. It has been linked to a range of health outcomes [14]. The BRS comprises six items answered on a 5-point scale from "strongly disagree" to "strongly agree". Examples of items include "I tend to bounce back quickly after hard times", "It does not take me long to recover from a stressful event", and "I usually come through difficult times with little trouble". After reversing the scores for negatively worded items, scores are added and averaged to produce an overall mean score between 1 and 5, with higher scores indicating greater resilience.

\section{Data collection}

The survey was conducted between May 2014 and August 2014, and was granted ethical approval from the La Trobe University Human Ethics Committee (Ref: FHEC 13-262). A survey pack containing two hard copy surveys was sent to each of the 1298 households in the town. We chose this method over other alternatives, such as cluster sampling, because the town is relatively small and we wanted to maximize the chance of every resident having access to the survey in order to obtain a sufficiently sized sample. Two copies were sent to each household in case more than one adult lived there, as would be likely for many households. Participation was voluntary and no incentive or reward was offered for participation. Residents who chose to participate first read background information about the study that was attached to the front of the survey. They were informed that only adults aged 18 years or older were permitted to complete the survey and their responses would be anonymous and kept confidential. Those who completed the survey posted it back to the research team using a reply paid envelope. Consent to participate in the study was assumed based on participants voluntarily completing and returning the survey.

\section{Analysis}

Descriptive statistics were used to provide an overview of the sample with regard to demographic variables and the community groups in which participants participated, including each group type/characteristic variable. Associations with psychological well-being were assessed with separate univariable linear regressions conducted for each group type/characteristic variable using scores on the SWEMWBS as the outcome variable. Because mental health often varies according to demographics [31], all regressions controlled for the demographic variables, that is, age, gender, employment status, country of birth, and number of years living in the town (age and years living in the town were included as continuous variables). To identify significant independent factors, variables that were associated with psychological wellbeing at $p<0.15$ were entered into a single multivariable regression while controlling for demographic variables. A cut-off of $p<0.15$ allowed for associations that were not quite significant in the univariable regressions but could be significant in the multivariable regression after taking into account other variables [32]. This same procedure of univariable regressions followed by a multivariable regression was repeated with scores on the Brief Resilience Scale as the outcome variable. In all regressions, standardized (beta) coefficients were computed for each category of a variable and Wald tests assessed the overall effect of each variable. All associations were treated as significant at $p<0.05$. Stata 11.1 (StataCorp, College Station, Texas, USA) was used to perform all analyses.

\section{Results}

\section{Sample profile}

Table 1 displays numbers and percentages of participants according to each demographic variable. As shown, a majority of participants $(63 \%)$ were aged 60 years or older and a little over half (58\%) were female. Close to one half (46\%) of participants were employed in fulltime, part-time, or casual work, and $45 \%$ were retired. Almost all were born in Australia (97\%) and three quarters $(75 \%)$ had lived in the town for 20 years or more. A large majority ( $83 \%)$ felt they were moderately or very much a part of their community but more than half (53\%) reported having little or no influence within their community.

\section{Community group participation}

Of the 176 participants in the study, 160 answered questions on a group that they felt was most important to them. A wide range of groups was reported. Examples included arts and crafts groups, sporting clubs and recreational groups (e.g., cricket club, football club, walking group), volunteer groups (e.g., fundraising groups, emergency services), youth clubs, and senior citizens' groups. Table 2 displays numbers and percentages of participants reporting on each group type and group characteristic variable in reference to their most important group. Two fifths (39\%) of the groups were primarily socialfocused groups. Close to one fifth (19\%) was primarily task-focused. Another one fifth (18\%) was reported as social and task-focused. Close to one quarter (24\%) were neither indicated as social nor task-focused. A majority of 
Table 1 Sample profile $(n=176)$

\begin{tabular}{|c|c|c|}
\hline & No. & Percent \\
\hline \multicolumn{3}{|l|}{ Gender } \\
\hline Male & 73 & 42 \\
\hline Female & 99 & 58 \\
\hline \multicolumn{3}{|l|}{ Age } \\
\hline $18-39$ & 17 & 10 \\
\hline $40-59$ & 46 & 27 \\
\hline $60+$ & 106 & 63 \\
\hline \multicolumn{3}{|l|}{ Employment status } \\
\hline Full-time & 37 & 22 \\
\hline Part-time or casual & 40 & 24 \\
\hline Unemployed & 12 & 7 \\
\hline Retired & 75 & 45 \\
\hline Other & 4 & 2 \\
\hline \multicolumn{3}{|l|}{ Country of birth } \\
\hline Australia & 169 & 97 \\
\hline Overseas & 5 & 3 \\
\hline \multicolumn{3}{|c|}{ Number of years living in town } \\
\hline Less than 20 years & 43 & 25 \\
\hline 20 years or more & 127 & 75 \\
\hline \multicolumn{3}{|c|}{ Feel a part of the community } \\
\hline Not at all & 6 & 3 \\
\hline A little & 23 & 13 \\
\hline To a moderate degree & 61 & 36 \\
\hline Very much & 81 & 47 \\
\hline \multicolumn{3}{|c|}{ Influence within the community } \\
\hline A little or none & 89 & 53 \\
\hline Some or a lot & 80 & 47 \\
\hline
\end{tabular}

participants belonged to groups that were formally organized $(81 \%)$ or had a group leader $(75 \%)$. Just over one third (36\%) reported belonging to a group that was organized hierarchically. However, most groups were not indicated as having strict rules (63\%) and were relatively relaxed/casual (61 \%). Less than half (46\%) had clearly defined roles for the group members.

The majority of participants reported that their group had existed for more than 20 years $(69 \%)$ and met one or more times a week (58\%). Just over one third (37\%) were in groups of fewer than 20 members while another third (36\%) were in groups of 50 or more members. Three quarters of participants $(76 \%)$ indicated that their group gained new members never, or only rarely or occasionally. Only $56 \%$ of participants reported their group having members who were similar to each other. Almost three quarters of participants $(73 \%)$ reported having some or a lot of influence within their group. This group was made up of 78 (50\%) participants who reported having some influence within their group and 36 (23\%) having a lot of influence within their group.

\section{Psychological well-being and community group participation}

Table 3 displays mean scores on the SWEMWBS according to the type and characteristics of the groups that participants nominated as their most important. In the univariable analyses, psychological well-being was found to be significantly greater among participants who reported having some or a lot of influence within their group $(\mathrm{F}[1,133]=5.51, p=0.02)$. This was the only significant factor from the univariable analyses. However, group influence was no longer significant in the multivariable analysis. Instead, group hierarchy was the only significant independent factor. Specifically, psychological well-being was significantly greater among participants in groups that were not organized hierarchically or, in other words, had equal-status relationships $(\mathrm{F}[1,120]=4.33, p=0.04)$.

\section{Resilience and community group participation}

Table 4 displays mean scores on the Brief Resilience Scale according to the type and characteristics of the groups that participants nominated as their most important. In the univariable analyses, resilience was found to be significantly greater among participants who reported their group having strict rules $(\mathrm{F}[1,132]=4.93, p=0.03)$, and among those who reported having some or a lot of influence within their group $(\mathrm{F}[1,134]=8.27, p=0.005)$. In the multivariable analysis, only group influence emerged as a significant independent factor $(\mathrm{F}[1,122]=4.39, p=0.04)$. Being in a group with strict rules was not significantly associated with resilience once other group variables were taken into account.

\section{Discussion}

Almost all participants in this household survey answered questions on a group to which they belonged and that was most important to them. There was considerable diversity within the groups reported in terms of whether they were social-focused, task-focused or a balance of both, and in terms of group characteristics (e.g., groups with or without leaders, hierarchical structures, strict rules, and clearly defined roles for members). Some groups gained new members often while many were less likely to do so. Some groups were relatively small while others had 50 or more members. Just over half of participants agreed that their group members were similar to one another, while less than half did not agree.

Group type did not emerge as a significant independent factor in the multivariable analyses for either psychological well-being or resilience. It would therefore appear that both social and task-focused groups have similar outcomes in this sample, at least with regard to the measures 
Table 2 Types and characteristics of community groups that participants nominated as their most important $(n=160)$

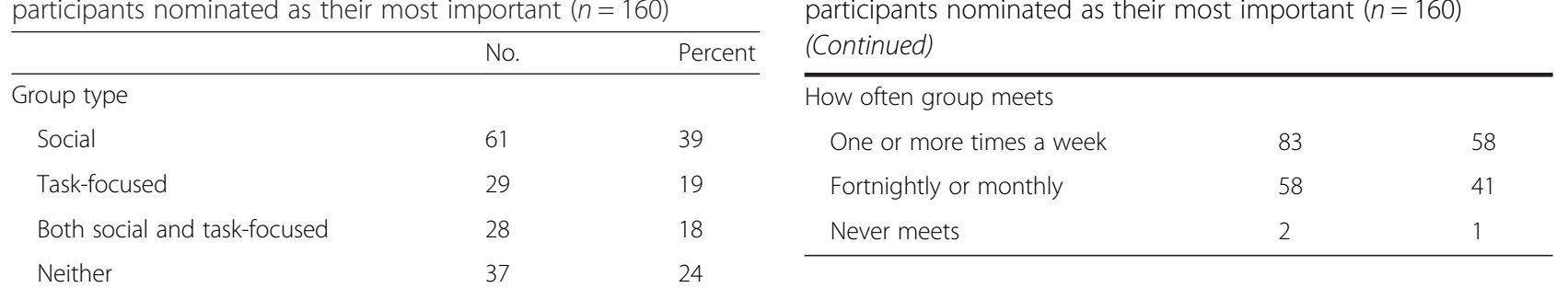

Formally organized

$\begin{array}{lll}\text { Yes } & 126 & 81 \\ \text { No } & 29 & 19\end{array}$

Hierarchical

Yes

56

No

Has strict rules

Yes

No

98

Relatively relaxed/casual

Yes

No

Has a leader

Yes

No

Group members have clearly defined roles

Yes

No

84

People in the group are similar to one another

$$
\text { Agree }
$$

Do not agree

Participants' influence within the group

Little or none

Some or a lot

Number of group members

0-19

20-49

$50+$

Length of time the group has existed

Less than 5 years

Between 5 and 20 years

More than 20 years

How often the group gains new members

Rarely or never

Often
Table 2 Types and characteristics of community groups that participants nominated as their most important $(n=160)$ (Continued)

we included in our study. With regard to group characteristics, only group hierarchy emerged as a significant independent factor, and only for psychological well-being. Participants reported greater psychological well-being if their most important group did not have a hierarchy or, in other words, had relatively equal-status relationships. This was regardless of whether the group was social or taskfocused and independent of other group characteristics.

There is little known about the role of equal-status relationships in groups on well-being. Research conducted in whole communities shows poorer health and wellbeing when there is less equality among community members, and this is attributed in part to stress and lower self-esteem from perceived status differences [33]. It may be that equal-status relationships in community groups produce a perceived sense of fairness where each group member feels included and respected equally. Having little or no hierarchy may also mean that more individuals are able to actively contribute in ways that are personally or socially significant to them. This, however, needs to be tested in further research, perhaps by examining the impact of changes in group structures on subsequent well-being outcomes.

A different pattern emerged for resilience. Group hierarchy appeared not to play a role. Rather, participants who reported having some or a lot of influence within their most important group were significantly more likely to be resilient than those who reported little or no influence. It is probable that having group influence is linked with an individual's sense of self-efficacy or sense of control over their environment, which is an important component of resilience [26]. It may be that providing opportunities for individuals to have some or a lot of influence within a group that is important to them helps foster resilience. This might also be best achieved in groups that enable equal-status relationships and roles. However, longitudinal research is needed to fully test the relationship between having a great deal of influence within a group and overall resilience. For example, while it is possible that some individuals gain a greater sense of self-efficacy and therefore greater resilience as a result of having influence within their group, it is also possible that some individuals who already display high levels of resilience tend to be elevated to positions in groups that give them influence. 
Table 3 Psychological well-being according to group types and characteristics $(n=160)$

\begin{tabular}{|c|}
\hline Group type \\
\hline Social $^{b}$ \\
\hline Task-focused \\
\hline Both social and task-focused \\
\hline Neither \\
\hline Formally organized \\
\hline Yes $^{\mathrm{b}}$ \\
\hline No \\
\hline Hierarchical \\
\hline Yes $^{\mathrm{b}}$ \\
\hline No \\
\hline Has strict rules \\
\hline Yes $^{\mathrm{b}}$ \\
\hline No \\
\hline Relatively relaxed/casual \\
\hline Yes $^{b}$ \\
\hline No \\
\hline Has a leader \\
\hline Yes $^{\mathrm{b}}$ \\
\hline No \\
\hline $\begin{array}{l}\text { Group members have clearly } \\
\text { defined roles }\end{array}$ \\
\hline Yes $^{\mathrm{b}}$ \\
\hline No \\
\hline
\end{tabular}

People in the group are similar to one another

Agree $^{\mathrm{b}}$
Do not agree

Participants' influence within the group

Little or none
Some or a lot
Number of group members
$0-19^{b}$
$20-49$
$50+$

Length of time the group has existed

Less than 5 years ${ }^{\mathrm{b}}$
Between 5 and 20 years
More than 20 years

$M \quad S D \frac{\text { Univariable }^{a}}{\beta \quad p} \frac{\text { Multivariable }^{a}}{\beta \quad p}$

\begin{tabular}{|c|c|c|c|}
\hline & 0.06 & 0.38 & Rarely or neverb \\
\hline $26.9 \quad 3.2$ & - & - & Occasionally \\
\hline $28.4 \quad 3.6$ & 0.17 & 0.08 & Often \\
\hline
\end{tabular}

$\begin{array}{llll}27.3 & 3.0 & 0.06 & 0.05\end{array}$$$
25.6 \quad 5.1-0.11 \quad-0.11
$$$$
\begin{array}{llllll} 
& & & 0.19 & - \\
27.1 & 3.9- & & \\
26.0 & 3.8 & -0.11 & & \\
& & & & \\
& & 0.07 & & \\
& & & & & \\
& & &
\end{array}
$$$$
26.0 \quad 3.2-
$$$$
27.5 \quad 4.1 \quad 0.16
$$$$
0.19^{*}
$$$$
\begin{array}{cccccc} 
& & & 0.14 & & 0.52 \\
27.5 & 3.7 & - & - & \\
26.6 & 3.9 & -0.12 & \multicolumn{2}{c}{-0.06}
\end{array}
$$$$
\begin{array}{lllllll} 
& & & 0.17 & & - \\
27.3 & 3.2 & - & & - & \\
26.3 & 4.7 & -0.12 & - &
\end{array}
$$

$27.0 \quad 3.8-$$$
26.6 \quad 4.2-0.03
$$$$
0.12
$$$$
27.3 \quad 2.9-
$$$$
\begin{array}{lll}
26.6 & 4.5 & -0.13
\end{array}
$$
0.65

$27.23 .9-$

$\begin{array}{lll}26.7 & 3.9 & -0.04\end{array}$ 0.02

25.63 .6 -

$27.5 \quad 3.9 \quad 0.21^{*}$ 0.16 0.44

$27.0 \quad 3.5$ -

$\begin{array}{lll}27.5 & 3.2 & 0.03\end{array}$

$\begin{array}{lll}26.6 & 4.7 & -0.10\end{array}$ 0.72
Table 3 Psychological well-being according to group types and characteristics ( $n=160)$ (Continued)

\begin{tabular}{|c|c|c|c|c|c|c|}
\hline $\begin{array}{l}\text { How often the group gains new } \\
\text { members }\end{array}$ & & & & 0.10 & & 0.60 \\
\hline Rarely or never ${ }^{b}$ & 25.8 & 3.6 & - & & - & \\
\hline Occasionally & 26.8 & 4.1 & -0.03 & & -0.08 & \\
\hline Often & 28.0 & 3.4 & 0.17 & & 0.02 & \\
\hline How often group meets & & & & 0.81 & & - \\
\hline One or more times a week ${ }^{\mathrm{b}}$ & 27.2 & 4.4 & - & & - & \\
\hline Fortnightly or monthly & 26.8 & 2.7 & -0.02 & & - & \\
\hline
\end{tabular}

Results are from univariable linear regressions conducted for each group type and characteristic variable and a single multivariable linear regression involving those variables that were associated with scores on the SWEMWBS at $p<0.15$ in the univariable regressions. Categories that significantly differ from the reference category are indicated by asterisks. ${ }^{a}$ Adjusted for all demographic variables. ${ }^{\mathrm{b}}$ Reference category. ${ }^{*} p<0.05$

Other research has found that the social groups in which people participate have major implications for their health and wellbeing [23]. Often, people who move out of one group and into another have changes to their health and well-being status, especially if those groups are important to their sense of identity [24]. Our findings provide specific information about the group characteristics most closely linked with well-being and resilience, and especially highlight the importance of having inclusive groups that promote equality and decision-making among all members. Governments, health authorities, and community leaders may wish to consider the potential benefits to community well-being, not only by promoting the formation and maintenance of community groups but particular kinds of community group environments. For example, these organizations could consider actively establishing a range of task and social-focused groups for community members to join that each have structures and rules that promote relatively equal-status relationships and enable group members to share decision-making and to have a sense of influence within the group. Groups that enable deeper levels of involvement from members may also be more sustainable, perhaps being more attractive for residents to join and to stay within the group. This is important because achieving sustainable levels of participation is vital to building community resilience [8].

There were several limitations to this study. The study was conducted in a single town, so we do not know whether patterns found in our data are specific to this town or apply across rural centers. Although it would seem unlikely that findings such as the link between well-being outcomes and individuals having influence within their group are not found in other communities, further studies are nevertheless needed elsewhere before drawing firm conclusions.

The sample for the study was skewed toward an older cohort. It is possible that a greater number of older 
Table 4 Resilience according to group types and characteristics $(n=160)$

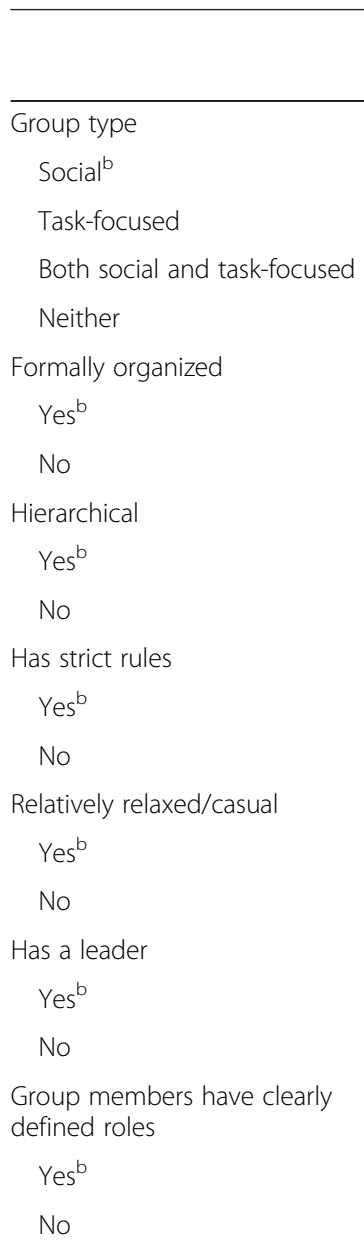

People in the group are similar to one another

Agree $^{\mathrm{b}}$
Do not agree
Participants' influence within
the group
Little or none $^{\mathrm{b}}$
Some or a lot
Number of group members
$0-19^{\mathrm{b}}$
$20-49$
$50+$

Length of time the group has existed

Less than 5 years ${ }^{\mathrm{b}}$
Between 5 and 20 years
More than 20 years

\begin{tabular}{|c|c|c|c|c|c|}
\hline \multirow[b]{2}{*}{ M } & \multirow[b]{2}{*}{ SD } & \multicolumn{2}{|c|}{ Univariable $^{a}$} & \multicolumn{2}{|c|}{ Multivariable } \\
\hline & & $\beta$ & $p$ & $\beta$ & p \\
\hline & & & 0.10 & & 0.45 \\
\hline 3.6 & 0.7 & - & & - & \\
\hline 4.0 & 0.6 & $0.21^{*}$ & & 0.11 & \\
\hline 3.6 & 0.7 & -0.03 & & -0.07 & \\
\hline
\end{tabular}

$\begin{array}{lll}3.7 & 0.6 & -0.02\end{array}$

$3.7 \quad 0.7 \quad-$

$\begin{array}{lll}3.5 & 0.8 & -0.16\end{array}$

$3.6 \quad 0.7-$

$\begin{array}{lll}3.7 & 0.6 & 0.08\end{array}$

$$
\begin{array}{lll}
3.8 & 0.7 & - \\
3.6 & 0.7 & -0.19^{*} \\
& & \\
3.6 & 0.7 & - \\
3.8 & 0.6 & 0.08 \\
& & \\
3.7 & 0.7 & - \\
3.7 & 0.7 & 0.07 \\
& & \\
& & \\
3.8 & 0.7 & - \\
3.6 & 0.7 & -0.12
\end{array}
$$

$$
\begin{array}{lll}
3.6 & 0.7 & - \\
3.8 & 0.6 & 0.11
\end{array}
$$

0.03 0.56

$-$ $-0.06$

$-$$$
3.4 \quad 0.8-
$$$$
3.8 \quad 0.6 \quad 0.25^{* *}
$$$$
0.19^{*}
$$

\begin{tabular}{|c|c|c|c|c|c|}
\hline $\begin{array}{l}\text { How often the group gains } \\
\text { new members }\end{array}$ & & & & 0.07 & \\
\hline Rarely or never ${ }^{\mathrm{b}}$ & 3.6 & 0.7 & - & & - \\
\hline Occasionally & 3.6 & 0.7 & 0.01 & & -0.02 \\
\hline Often & 3.9 & 0.6 & 0.22 & & 0.09 \\
\hline How often group meets & & & & 0.83 & \\
\hline One or more times a week ${ }^{\mathrm{b}}$ & 3.7 & 0.7 & - & & - \\
\hline Fortnightly or monthly & 3.6 & 0.7 & -0.02 & & - \\
\hline
\end{tabular}$$
0.42
$$$$
3.7 \quad 0.7 \quad-
$$$$
\begin{array}{lll}
3.8 & 0.5 & 0.01
\end{array}
$$$$
\begin{array}{lll}
3.5 & 0.8 & -0.11
\end{array}
$$

$3.8 \quad 0.5-$

$\begin{array}{lll}3.7 & 0.7 & -0.09\end{array}$ $\begin{array}{lll}3.6 & 0.8 & -0.14\end{array}$
Table 4 Resilience according to group types and characteristics $(n=160)$ (Continued)

Results are from univariable linear regressions conducted for each group type and characteristic variable and a single multivariable linear regression involving those variables that were associated with scores on the Brief Resilience Scale at $p<0.15$ in the univariable regressions. Categories that significantly differ from the reference category are indicated by asterisks. ${ }^{a}$ Adjusted for all demographic variables. ${ }^{b}$ Reference category. ${ }^{*} p<0.05$ ** $p<0.01$

people in the town participate in community groups than younger people because many are retired and may therefore have more time to attend group meetings and to take on group responsibilities. Because many of the questions in the survey targeted experiences of group participation, it is also possible that those who were not participating in community groups were less likely to have finished the survey. That said, our study still included a large proportion of participants younger than 60 years old and our main findings were independent of age. Researchers in the future may wish to consider ways of encouraging younger participants, especially those aged 30 years and younger. Offering incentives may be one possibility. Approaching groups with younger members may be another.

The response rate for the survey was lower than expected. Although the sample was certainly large enough to conduct multivariable analyses, it is possible that those who responded were different to non-responders. One possibility is that responders may have included group leaders. We did not ask participants whether they were leaders within their groups. It is worth noting, however, that $25 \%$ reported belonging to groups that did not have leaders and only $23 \%$ reported having a lot of influence within their group, so it is perhaps unlikely that a large number of participants were group leaders. That said, it is recommended that future studies collect more data on the specific roles that participants have within their groups to see if group role is also a factor in psychological wellbeing and resilience. Given its moderate sample size, this study should also be considered as a preliminary investigation into links between well-being and group types and characteristics. Further studies ought to be conducted in the future that seek to corroborate our findings using larger samples.

We did not collect data on education or income. It is possible that individuals with greater socioeconomic status 
are more likely to be awarded roles within groups that give them more influence. We therefore do not know whether there are links between socioeconomic status, group participation, and group influence. We also do not know whether socioeconomic status plays any role in links between well-being and equal-status relationships within groups. It is therefore advisable that future work in this area collects data on socioeconomic status and factors these data into analyses to confirm its role in outcomes.

Group type was classified as primarily social-focused, primarily task-focused, or both. Although we computed a "neither" category for those participants who did not indicate that their group was either social or task-focused, it is not clear what types of groups would fit this category. In some cases, participants may not have fully understood what we meant by social or task-focused, and therefore did not answer at all. However, it is also possible that some participants had a different idea in mind about how to categorize their group. As mentioned earlier, Lickel and colleagues conducted a cluster analysis of groups and identified four broad types [25]. In addition to socialfocused and task-focused groups, they identified loose associations (such as people living on the same street) and social categories (such as people having similar ethnic backgrounds). Neither of these types are organized groups as such, and do not appear to apply to the community groups that were the focus of this study. Indeed, social categories may exist without any interaction between people who belong within that category. In any case, only 37 out of 160 participants (who answered questions about group participation) did not indicate that their group was social or task-focused, but it may be worth gathering more information in future research to gain a better understanding of reasons behind particular response patterns to questions such as these and whether some participants have different ideas about how to categorize their group.

Finally, we examined the group that participants nominated as their most important. As mentioned earlier, personally important groups are more likely to have an impact on well-being [23, 24], and this is a strong reason for focusing on participants' most important group. However, a more complex study of all the groups to which participants belong may provide a more complete picture of the role of different kinds of groups in overall wellbeing and resilience. For example, based on the findings of the present study, it may be possible that people who belong only to groups with equal-status relationships have better well-being outcomes than those who belong to only one equal-status group and several hierarchical groups. Collecting such data can be challenging if some participants belong to a large number of groups, but this may be worth considering in future research to build a more comprehensive picture of the connections between community group participation and well-being.

\section{Conclusions}

This study examined community group participation and its links with psychological well-being and resilience from a household survey conducted in a medium-sized rural Australian town. Participants focused on their membership of a group that was most important to them. We found that participants with the greatest psychological well-being belonged to groups without hierarchies. We also found that participants with the greatest levels of resilience reported having some or a lot of influence within their group. Our findings also correspond with other research showing close links between community participation, health, and social support. That said, our sample could have been larger. Our sample also consisted mostly of older people. Future studies are therefore recommended that involve larger and more diverse samples before drawing firm conclusions. For now, our findings suggest that specific aspects of the group environment may be linked more strongly with psychological wellbeing and resilience, and could potentially be considered in policy settings that seek to promote community group participation for improving health outcomes in rural communities.

\section{Ethics approval and consent to participate}

Ethical approval for this study was granted by the La Trobe University Human Ethics Committee (Ref: FHEC 13-262). Consent to participate in the study was assumed based on participants voluntarily completing and returning the survey.

\section{Consent for publication}

Not applicable.

\section{Availability of data and materials}

Data are not available to be shared due to participants consenting to participate in the study on condition that data would not be shared. Additional file 1 has been provided that makes available the exact wording of questions on community group participation.

\section{Additional file}

Additional file 1: Survey questions relating to the participant's most important group. (PDF $339 \mathrm{~kb}$ )

\section{Abbreviations}

BRS: Brief Resilience Scale; SWEMWBS: Short Warwick Edinburgh Mental Well-Being Scale.

Competing interests

The authors declare that they have no competing interests.

Authors' contributions

$A L, G F, J F, A K, L B$, and $E B$ designed the study. $A L, G F, E B$, and $K C$ collected the data. $A L$ analyzed the data. All authors contributed to the interpretation 
of the data. AL wrote the first draft of the manuscript. All authors revised the manuscript and made substantive intellectual contributions to the final version. All authors approved the final version.

\section{Acknowledgements}

We wish to thank Jennifer Blackman for her assistance with data entry.

\section{Funding}

This research was supported by a grant awarded from La Trobe University's Building Healthy Communities Research Focus Area.

\section{Author details}

${ }^{1}$ Australian Research Centre in Sex, Health and Society, School of Psychology and Public Health, La Trobe University, 215 Franklin Street, Melbourne, Victoria 3000, Australia. ${ }^{2}$ Institute for Human Security and Social Change, La Trobe University, Melbourne, Australia. ${ }^{3}$ Rural Health School, La Trobe University, Melbourne, Australia. ${ }^{4}$ Rural Health Academic Centre, University of Melbourne, Melbourne, Australia.

\section{Received: 8 October 2015 Accepted: 30 March 2016}

Published online: 08 April 2016

\section{References}

1. Australian Bureau of Statistics. 3218.0-Regional Population Growth, Australia, 2009-10. http://www.abs.gov.au/ausstats/abs@.nsf/Products/3218.0 200910 Main+Features Main+Features?OpenDocument. Accessed 5 May 2015

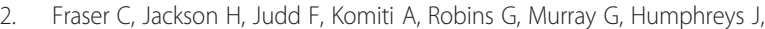
Pattison $P$, Hodgins $G$. Changing places: the impact of rural restructuring on mental health in Australia. Health Place. 2005;11(2):157-71.

3. Inder KJ, Lewin TJ, Kelly BJ. Factors impacting on the well-being of older residents in rural communities. Perspect Public Heal. 2012;132(4):182-91.

4. Burch D, Rickson R. Industrialised agriculture: agribusiness, inputdependency and vertical integration. In: Lockie S, Bourke L, editors. Rurality bites: the social and environmental transformation of rural Australia. Sydney, Australia: Pluto Press; 2001.

5. Australian Bureau of Statistics. 2071.0-Reflecting a nation: stories from the 2011 census, 2012-2013. http://www.abs.gov.au/ausstats/abs@.nsf/Lookup/ 2071.0main+features602012-2013. Accessed 5 May 2015.

6. Davis $\mathrm{S}$, Bartlett $\mathrm{H}$. Review article: healthy ageing in rural Australia: Issues and challenges. Australas J Ageing. 2008;27(2):56-60.

7. Wakerman J, Humphreys JS, Wells R, Kuipers P, Entwistle P, Jones J. Primary health care delivery models in rural and remote Australia: a systematic review. BMC Health Serv Res. 2008;8(1):276.

8. Kenny A, Farmer J, Dickson-Swift V, Hyett N. Community participation for rural health: a review of challenges. Health Expect. 2015;18(6):1906-17.

9. Farmer J, Hill C, Muñoz S-A, editors. Community co-production: social enterprise in remote and rural communities. Cheltenham, UK: Edward Elgar; 2012.

10. OECD. Strategies to improve rural service delivery. Paris, France: Organisation for Economic Co-operation and Development; 2010

11. Hegney DG, Buikstra E, Baker P, Rogers-Clark C, Pearce S, Ross H, King C, Watson-Luke A. Individual resilience in rural people: a Queensland study, Australia. Rural Remote Health. 2007;7(4):1-13.

12. Davydov DM, Stewart R, Ritchie K, Chaudieu I. Resilience and mental health Clin Psychol Rev. 2010;30(5):479-95

13. Smith BW, Dalen J, Wiggins K, Tooley E, Christopher P, Bernard J. The Brief Resilience Scale: assessing the ability to bounce back. Int J Behav Med. 2008:15(3):194-200.

14. Smith BW, Tooley EM, Christopher PJ, Kay VS. Resilience as the ability to bounce back from stress: a neglected personal resource? J Posit Psych 2010;5(3):166-76

15. Cohen S, Wills TA. Stress, social support, and the buffering hypothesis. Psych Bull. 1985;98(2):310-57.

16. Kawachi I, Berkman LF. Social ties and mental health. J Urban Health. 2001;78(3):458-67

17. Connor KM, Davidson JR. Development of a new resilience scale: the Connor-Davidson Resilience Scale (CD-RISC). Depress Anxiety. 2003:18(2):76-82.

18. Lyons A, Hosking W, Rozbroj T. Rural-urban differences in mental health, resilience, stigma, and social support among young Australian gay men. J Rural Health. 2014;31(1):89-97.
19. Hyett N, Scholar D, Kenny A, Dickson-Swift V, Farmer J. How can rural health be improved through community participation? Deeble Institute Issues Brief No 2. Canberra, Australia: Deeble Institute; 2014.

20. Hofferth SL, Iceland J. Social capital in rural and urban communities. Rural Sociol. 1998;63(4):574-98.

21. Woolvin M, Rutherford A. Volunteering and public service reform in rural Scotland: research report. Edinburgh, Scotland: SRUC Rural Policy Centre; 2013.

22. Cohen S, Mermelstein R, Kamarck T, Hoberman HM. Measuring the functional components of social support. In: Sarason IG, Sarason BR, editors. Social support: theory, research and applications. Amsterdam, Netherlands: Springer; 1985. p. 73-94.

23. Jetten J, Haslam C, Haslam SA. The social cure: identity, health and well-being. East Sussex, UK: Psychology Press; 2012.

24. Jetten J, Haslam C, Haslam S, Dingle G, Jones JM. How groups affect our health and well-being: the path from theory to policy. Social Issues and Policy Review. 2014;8(1):103-30

25. Lickel B, Hamilton DL, Wieczorkowska G, Lewis A, Sherman SJ, Uhles AN. Varieties of groups and the perception of group entitativity. J Pers Soc Psychol. 2000;78(2):223-46.

26. Schwarzer R, Warner L. Perceived self-efficacy and its relationship to resilience. In: Prince-Embury S, Saklofske DH, editors. Resilience in children, adolescents, and adults. New York, NY: Springer; 2013. p. 139-50.

27. Reker GT, Peacock EJ, Wong PT. Meaning and purpose in life and well-being: a life-span perspective. J Gerontol. 1987:42(1):44-9.

28. Alston M. Globalisation, rural restructuring and health service delivery in Australia: policy failure and the role of social work? Health Soc Care Community. 2007;15(3):195-202.

29. Leach CW, van Zomeren M, Zebel S, Vliek ML, Pennekamp SF, Doosje B, Ouwerkerk JW, Spears R. Group-level self-definition and self-investment: a hierarchical (multicomponent) model of in-group identification. J Pers Soc Psychol. 2008;95(1):144-65.

30. Stewart-Brown S, Tennant A, Tennant R, Platt S, Parkinson J, Weich S. Internal construct validity of the Warwick-Edinburgh Mental Well-being Scale (WEMWBS): a Rasch analysis using data from the Scottish Health Education Population Survey. Health Qual Life Outcomes. 2009;7(15):15.

31. Slade T, Johnston A, Teesson M, Whiteford H, Burgess P, Pirkis J, Saw S. The mental health of Australians 2: report on the 2007 National Survey of Mental Health and Well-being. Canberra, Australia: Department of Health and Ageing; 2007.

32. Hosmer DW, Lemeshow S. Applied logistic regression. New York, NY: John Wiley; 1989.

33. Wilkinson R, Pickett $K$. The spirit level: why equality is better for everyone. London, England: Penguin; 2010

\section{Submit your next manuscript to BioMed Central and we will help you at every step:}

- We accept pre-submission inquiries

- Our selector tool helps you to find the most relevant journal

- We provide round the clock customer support

- Convenient online submission

- Thorough peer review

- Inclusion in PubMed and all major indexing services

- Maximum visibility for your research

Submit your manuscript at www.biomedcentral.com/submit 